\title{
La inscripción intermedial en el texto postdramático
}

\author{
Luis Thenon
}

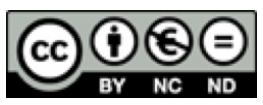

Esta obra está bajo una licencia Creative Commons

Reconocimiento-No comercial-Sin Obra Derivada 


\title{
La inscripción intermedial en el texto postdramático ${ }^{1}$
}

\author{
Dr. Luis Thenon \\ Profesor, Universidad Laval, Canadá \\ Luis.Thenon@lit.ulaval.ca
}

Recibido: 28 de setiembre de 2016 Aprobado: 28 de octubre de 2016

\section{Resumen}

Este artículo aborda un conjunto de consideraciones estéticas y técnicas en torno a la problemática planteada por el espacio de creación escénica condicionado por las tecnologías numéricas. En consonancia con las reconfiguraciones conceptuales que implican los nuevos universos intermediales, se plantea la necesaria adecuación de las escrituras creativas, dentro del marco planteado por el concepto de teatro postdramático. De conformidad con las propuestas teóricas de Silvestra Mariniello sobre las condiciones de la intermedialidad, este trabajo propone puntualizar y analizar ciertos elementos que determinan los nuevos entornos de las escrituras teatrales actualizadas y de las creaciones literarias posdramáticas, teniendo en cuenta la integración conceptual de los desarrollos escripto-visuales y escripto-sonoros, dentro de una estructura dialógica de configuraciones múltiples.

Palabras clave: intermedialidad; arte numérico; texto postdramático; escritura intermedial

\begin{abstract}
This article addresses some aesthetics and technical considerations on the problematic contemplated by the space of scenic creation, conditioned by the numerical technology. In accordance with the concep-

${ }^{1}$ La base teórica de este estudio, se desarrolló en el marco de una investigación posdoctoral ("Bases epistémicas para una historia del teatro actual”) adscrita al Centro de Investigaciones Históricas de América Central y al Posgrado Centroamericano en Historia, UCR, 2013/14/15.
\end{abstract}


tual reconfigurations that the new intermediate universes implied, the necessary adequacy of creative writing in the frame of the Post-dramatic Theatre is set out. Consistent with Silvestra Mariniello's theoretical proposals on the conditions of intermediality, this work proposes to specify and analyze certain elements that determine the new environments of the theatrical updated writings and the postdramatic literary creation. It takes into consideration the conceptual integrations of the scripto-visual and scripto-audio developments, within the dialogical structure of multiple configurations.

Keywords: intermediality; numerical art; post-dramatic text; intermediate wrinting 
Cuando se aborda el problema de las transfiguraciones que involucran transversalmente la integración de las tecnologías en el proceso de concepción y de producción de una obra de arte, parece necesario determinar algunos límites, puesto que la incidencia de las condiciones tecnológicas entendidas en un sentido amplio, se inscribe de manera continua en el devenir histórico de los oficios del arte. Los desarrollos técnicos contribuyen, también, al auge de reconfiguraciones polisémicas, y de nuevos procesos de metaforización. Rosa de Diego, en el prólogo de La máquina escénica: drama, espacio, tecnología, aborda el tema al decir que:

La máquina es también metáfora, es decir, construcción de un sentido. Puede producir entonces efectos simbólicos, metaforizantes, o ser un elemento operador de lo maravilloso, de lo fantástico, de la utopía, del exotismo o de la magia. Con todas sus consecuencias y desviaciones, como la relación entre la técnica y el cuerpo ... La tecnología, en suma, se presenta como factor determinante de la construcción de un imaginario. (2001, pp. 9-10).

En los últimos treinta años, estos procesos se han multiplicado exponencialmente con el advenimiento masivo de las tecnologías numéricas y la aceleración de las transfiguraciones que las presiones mediáticas imprimen al conjunto de las expresiones del arte. La estética, como reflexión filosófica sobre el arte (Jiménez, 1997, p. 9) se confronta a veces a las vicisitudes de lo inmediato y aparece entonces, con límites inexactos. La intención de ocupar el lugar del crítico induciendo a la definición de "criterios conformes a cánones dictados de antemano ... . Tal es la tentación de todo academicismo, incluso del esteticismo" (Jiménez, 1997, p.11). Pero como bien lo indica más adelante el mismo autor:

es un hecho que la estética ha sido discreta en relación al arte en devenir, timorata ante las obras nuevas, comúnmente inclinada al estudio de las creaciones reconocidas, santificadas por la posteridad, que a pronunciarse sobre el valor de cosas nuevas, porque son precisamente demasiado nuevas. Esta prudencia, que remonta de hecho a los orígenes de la estética filosófica -Kant y Hegel se abstuvieron prudentemente de citar los grandes artistas de sus tiempo-, no ha favorecido el reconocimiento de la estética como discurso innovador sobre las artes (Jiménez, 1997, p. 12).

Sin embargo, siguiendo el pensamiento de Couchot e Hillare (2003):

Sería ilusorio creer que con el tiempo las cosas se tornarán más claras, filtradas por la cultura y sus modos de transmisión. Porque lo numérico transforma también nuestra relación con el tiempo, nuestra manera de vivirlo o de revivirlo, de anticiparlo, de sustraernos del tiempo a través del arte. Con lo numérico, cambiamos también la historia (p. 11).

Parece claro que el impulso de las artes numéricas y el advenimiento del conjunto de las tecnologías de lo numérico, en el cambiante mundo de las artes actuales, produce una tensión 
que dificulta la continencia, al observar cómo, incluso las artes tradicionales, se transforman y se reacondicionan en sus modos de producción, al contacto con las tecnologías numéricas. Al respecto, parece indicado observar que si

el arte numérico se apoya sobre una tecnología «de avanzada», este no se reduce a los efectos tecnológicos. Da testimonio de una gran riqueza y de una inmensa variedad, atravesada por tendencias y estéticas diferentes, incluso opuestas, pero que se nutren del mismo paradigma de la hibridación" (Couchot e Hillare, 2003, p. 10).

Como bien lo indica Simon Hagemann en su libro Penser les médias au théatre: des avant-gardes historiques aux escenes contemporaines "determinar si el teatro debe o no ser considerado como un media, depende de la manera en que se definan ambos términos, medias y teatro" (2013, p. 20). Para este autor, es posible considerar así el teatro en tanto es un vector de información, aunque no comparable a la radio, al cine o a la televisión y, aún menos, a las actuales redes ante las cuales, incluso el cine ha perdido también en gran parte -al igual que el teatro anteriormente- su condición de medio de comunicación de masas. Pero esto no es tan sencillo como parece proponerlo el autor citado. Al tratar la problemática general de los medias, parece inconveniente reducir el término a los medios de comunicación únicamente en función de su capacidad de producir y transportar información masivamente.

Según lo exponía Rudolf Stöber (2003) hace más una década, en el devenir de las transformaciones culturales "los nuevos medias retoman (constantemente) a los antiguos medias, sus estructuras narrativas, sus formatos, sus géneros y sus reglas estéticas" (citado por Hagemann, 2013, p.18). A su vez, los nuevos medias aportan a los medias originales una presión que los obliga a reinventarse, a cuestionar sus cánones estéticos ${ }^{2}$ y a redefinir su lugar en el espectro cultural. Esta constante reinvención de los medias tiene consecuencias directas en su percepción como tal, en el análisis de sus características, en su condición histórica al interior del amplio espectro de los medias, en sus variables de incidencia en los constructos culturales. Silvestra Mariniello trabaja sobre la idea de que:

estamos experimentando una profunda crisis en nuestra (moderna) literacy y, sugiere, que la noción de intermedialidad podría ayudar a comprender la nueva literacy. Contra toda una tradición filosófica que primero trata de comprender y nombrar a las sustancias, y luego, captar sus relaciones, la intermedialidad se enfoca en las relaciones y entiende las sustancias como puntos relacionales que demandan (y permiten) un profundo cambio en la manera como pensamos y operamos (2009, p. 59).

\footnotetext{
${ }^{2}$ Véase: Thenon, L. (2005). Las dramaturgias y el desafío tecnológico: reflexiones para las nuevas escrituras del drama, Revista de la Asociación de directores de escena en España, Madrid, 106, pp. 42-48.
} 
El teatro, como uno más en el conjunto de los medias, también está subordinado a estos grados de historicidad, y lo que ayer era un factor comunicacional de incidencia mayor, se puede volver hoy marginal en relación directa con los desarrollos tecnológicos y la evolución de las reconstrucciones sociales que ellos implican. Pero evoluciona también, en su historicidad, el concepto de medias, lo que nos obliga, como lo proponen Jay David Bolter y Richard Grusin (1999), a pensarlos desde su condición de remediación. Se abre aquí una interrogante de consecuencias vastas, puesto que la realfabetización medial (pensar y apropiarse del uso de los medias), significa incuestionablemente incluir nuevas reflexiones sobre la estética, observar los modos de utilización, reconstruir de manera continua el mapa de "desarrollo y de la relativa función de los medias" (Hagemann, 2014, p. 20).

La ruptura medial logocéntrica, tal como la presentaban la radio, los medios impresos e incluso la televisión en sus comienzos, entra en una crisis provocada por la irrupción de las redes en las esferas cotidianas del vivir. En estas, se produce inicialmente una transformación que pone a la implementación de arquitecturas escripto-visuales en el centro de los constructos comunicacionales. Pero paulatinamente, la imagen-texto retoma un amplio espacio en el espectro medial. Esto no sucede sin un profundo cambio conceptual del uso de la palabra, el mensaje-texto reemplaza cada vez más el uso de la voz como base de la comunicación cotidiana a distancia (telefónica), pero ese mensaje-texto implica una reconstrucción sintáctica mayor, una reducción del uso del logos en su dimensión metafórica, una reescritura abreviativa que poco a poco va condicionando el conjunto de las estéticas discursivas. En el continuum de este movimiento pendular, la imagen-texto deja luego, gradualmente, su protagonismo a la condensación discursiva del mensaje-voz. Esto nos obliga a observar la totalidad que implica esta nueva literacy, el uso y apropiación de los medios en el cauce de una constante realfabetización comunicativa que transforma continuamente las configuraciones expresivas de las relaciones sociales y abre un nuevo espacio de investigación a las consideraciones de orden estético.

En el campo del arte teatral, debemos tener en cuenta que la presión que las tecnologías numéricas ejercen sobre el conjunto de expresiones escénicas, redefine tanto las condiciones formales de la producción como las prácticas conceptuales y los desarrollos técnicos necesarios en el conjunto de lenguajes y acciones creativas implicadas ${ }^{3}$. Al referirse a la problemática planteada por la relación entre la escena teatral y las entonces llamadas "nuevas tecnologías", Chantal Hébert e Irène Perelli-Contos sostienen que:

es seguro que las nuevas tecnologías, con los nuevos valores que vehiculan, modifican el trabajo del actor. Ellas incitan, tanto como invitan al espectador, a depositar otra mirada

${ }^{3}$ Véase: Thenon, L. (2002). Proyectos de formación actoral: La formación del actor y la dramaturgia intermedial, $A D E-T e a t r o, 92$, pp. 172-177. 
sobre sí mismo, sobre el mundo que lo rodea y sobre el arte teatral. También, las nociones de presencia y de energía, de real y de realidad, de artificial y de virtual, de reflejo y de apariencia, de representación, etc., deben ser redefinidas, puesto que la "esencia" del teatro en la era tecnológica parece haberse descentrado, pasando del trabajo del actor al trabajo de las formas (2006, p. 53).

Las escrituras artísticas, literarias, visuales, auditivas, se exponen constantemente a la velocidad del cambio y a la adecuación de sus propuestas estéticas, en las que se instala la supremacía del movimiento como inducción matricial. El texto dramático, desde su existencia de texto preescénico -el teatro visto desde su doble función de obra de arte en el espacio y de literatura abierta- está también determinado por la condición específica de la multimedialidad. Cuando Dick Higgins (1966), introduce el término de intermedias, se produce un cambio mayor en la generación de sentidos críticos. Al respecto, Jürgen Muller (2000) dice que "un producto mediático deviene intermediático cuando la coexistencia multimediática de sus elementos [...] se transfiere en una simbiosis conceptual según la cual las refracciones y los rechazos estéticos abren nuevas concepciones de la experiencia y de la comprensión" (citado por Hagemann, 2013, p. 26). A esto se refieren Hébert y Perelli-Contos cuando dicen que:

Si antes el espectador estaba frente a la imagen, toda una corriente del teatro actual, y particularmente el teatro de la imagen, lo pone ahora en lo visual, obligándolo a cambiar sus hábitos perceptivos y a transformarse en espect(a)ctor. Ante esto, el espectador se vuelve, más que testigo de realidades o un receptor pasivo de imágenes, un agente organizador del acto de ver (2006, p. 54).

También debe tenerse en cuenta la evolución que los productos intermediales imprimen al complejo sistema de recepción que la sociedad hipermediática y las prácticas propuestas por el arte numérico redefinen, según lo que exponen Edmond Couchot y Norbert Hillaire (2003). Esto está incluido en lo que Mariniello (2009) llama la nueva literacy, que nos parece importante entender desde el pensamiento de Milad Doueihi cuando sostiene que:

lo numérico, a pesar de un fuerte componente técnico, que siempre es necesario cuestionar y vigilar sin descanso, ... se ha convertido en una civilización que se distingue por la manera según la cual modifica nuestra mirada sobre los objetos, las relaciones y los valores, y que se caracteriza por las nuevas perspectivas que introduce en el campo de la actividad humana. (2011, pp. 9-10)

A medida que el texto postdramático abandona su función de literalidad condicionante del espectáculo teatral, absorbe progresivos grados de cinematicidad. Esto lleva a la introducción de alternativas y variantes de creación que en el espacio escénico se manifiestan bajo diversas formas, tales como el quiebre de la unidad lineal de los discursos. Esto también incide en 
el personaje como construcción referencial el que, en sintonía con las rupturas propuestas por el nouveau roman, entra en estado de crisis.

Tanto en el cine como en el teatro y en la novela, se resquebraja el efecto de realidad, perdiendo el personaje, para retomar lo dicho por Ryngaert y Sermon, su condición de lente convergente de ilusión de lo posible (2006, p. 64). La dilución de la primacía del texto -en pos de un complejo juego de interacciones entre los lenguajes cambiantes del teatro postdramático- está fuertemente condicionada por los cambios profundos que se operan en el espacio dramático. De esta forma, abandona este su estética imitativa ordenada bajo la forma de una alternancia de acciones verbales, para reconstruirse sobre la base de un espacio múltiple, discontinuo, variable, en el que las secuencias dramáticas elaboran su acción escénica bajo la rúbrica de una dependencia estrecha con las escrituras lumínicas; espacio y luz como materia de la superposición y de la recomposición de los relatos y ya no como lugar de continencia referencial directa. Estos cambios, a veces violentos, a veces progresivos, van constituyendo ese nuevo cuerpo que Lehmann (2002), reúne bajo la apelación ya consagrada de teatro postdramático. En este espacio rediseñado, en el que conviven tiempos y lugares múltiples y superpuestos, se prepara decididamente la irrupción de los lenguajes tecno-sonoros y tecno-visuales. La imagen hace ritmo, condiciona y renueva los supuestos estados de presencia, modifica la preconcepción frontal de la recepción, sumerge al espectador en el centro de una matriz espectacular de límites imprecisos y cambiantes. Mariniello piensa la intermedialidad como:

un conjunto de condiciones que hacen posible los cruzamientos y la concurrencia de los medias, el conjunto de figuras que los medias producen al cruzarse, la disposición potencial de los puntos de una figura en relación con los de otra. La intermedialidad es el conocimiento de sus condiciones, de la posibilidad de múltiples figuras, de la eventualidad con que los puntos de una figura remiten a los de otra. [...] es el conocimiento de sus condiciones, [de la posibilidad de múltiples figuras] (2009, p.64).

Punto de convergencia, espacio definido por la convención en el que se cruzan los caminos de una escritura de relaciones múltiples, la escena postdramática, espejo del mundo intermedial, concretiza la idea de una fábrica textual en la que lo audible y lo visible forman un cuerpo indisociable. Los modos enunciativos se integran en un espacio en el que los discursos de la narración dramática manifiestan las múltiples identidades ficcionales a través de una red versátil, en la que los funcionamientos narrativos son indisociables de lo que se expone a la mirada, lo que se deja ver, lo que se reconstruye en capas sucesivas de sentido. Esta red intermedial se erige en el espacio escénico como principal agente de acción y, al hacerlo, determina una nueva arquitectura dramatúrgica. Ryngaert (2006) hace referencia a Joseph Danan (2004)4 quien al trabajar sobre el problema de la mutación de la acción, "constata la desherencia de las

${ }^{4}$ Véase: Danan, J. (2004). Dossier Mutation de l’action, Présentation, en L’Annuaire théâtral, no 36, pp. 9-54. 
formas canónicas de la acción, lo que ["pone" en estado de observación crítica] la posibilidad mimética [incluyendo al personaje]" (p. 20). Danan, al cuestionarse sobre las nuevas formas de la acción dramática, no puede sino advertir que una de las avenidas de mayor incidencia en la escena actual, está profundamente asociada a la noción de movimiento. El flujo constante y masivo de los nuevos medias en el espacio teatral, incluyendo el espacio propio de la escritura post-dramática, no invalida la noción tradicional de acción dramática, pero incluye, sin lugar a dudas, un nuevo sistema de substituciones. El espacio escénico, en sus múltiples configuraciones, determina en su evolución diversos grados de realidad producidos por una reconfiguración de los universos poéticos o metafóricos. Esta nueva ficcionalidad se inscribe también en el texto postdramático como una reconversión de las unidades temporales, se manifiesta en las superposiciones fragmentadas y en duraciones temporales subjetivamente irresueltas. La acción dramática se vuelve permeable a la intemporalidad, aumenta su capacidad transformacional en una estructura de superposiciones miméticas que se anulan y se reconstruyen al mismo tiempo. Así, propone un nuevo paradigma de identificación en el que el sistema de interacción verbal que constituía el eje central del texto dramático se viste de discontinuidad, busca sus puntos de fuga en la relación entre la fragmentación de la palabra y su simultaneidad con los discursos de la imagen proyectada, constituyendo así un espacio continuo de intermediaciones. Mariniello sostiene que:

La intermedialidad ... se convierte en el lugar a partir del cual [podemos] ser testigos de la lucha entre dos literacies, dos regímenes de conocimiento, ... El espacio de la intermedialidad es el espacio híbrido donde el discurso se abre a lo visible y la visualidad se convierte en discursiva en un movimiento que perturba la construcción lingüística y filosófica que las tenía separadas. La intermedialidad es diferente a la intertextualidad o la interalteridad, ya que ella implica la centralidad de la técnica en la comprensión de dinámicas diferentes (2006, p. 77).

Esta dinámica, de la que habla la teórica canadiense, establece en el texto postdramático un sistema de resonancias y de fricciones que opera en el conjunto del movimiento escénico que el texto induce, produciendo un reforzamiento de las relaciones oscilatorias, lo que implica un cambio radical en el continuum de la acción. Esto impulsa, en primera instancia, un juego de frecuencias rítmicas en el que los conflictos ya no solo se basan en la oposición dialógica y/o filosófica de los personajes, sino en un amplio juego de ideogramas compuestos por la intermitente relación de los discursos mediales. Podríamos sugerir que en ese sistema de movimientos, el espacio y el tiempo en que los discursos mediales se interrelacionan, está también regido por la fluidez combinatoria que se produce en lo que metafóricamente se puede entender como la superficie de contacto de cada discurso medial, su viscosidad, su índice de resistencia y, al mismo tiempo, su capacidad combinatoria que le permite interactuar con el entorno discursivo. 
La presencia cada vez más importante de discursos visuales y de diseños sonoros complejos en el espacio escénico, interactúan con el habla de los personajes (principal materia del texto dramático). Al hacerlo, condicionan la intensidad de las posibles relaciones predominantes entre los cuerpos presenciales y los cuerpos virtuales, entre la voz presencial y el universo sonoro, creando también un orden de continuidad y de discontinuidad entre los universos escenográficos materiales y aquellos constituidos de imagen/luz.

La apertura y la remodelación de los espacios percibidos a través de la manipulación de los diseños sonoros, confieren también al conjunto una nueva dinámica referencial. Ryngaert dice que la palabra, el habla de los personajes en el teatro actual, establece:

una nueva dialéctica ... cada vez más compleja entre la identidad faltante y las palabras de orígenes diversos, en el seno de una escritura que participa del comentario, de la autobiografía, de la repetición, de la constitución de listas [como, por ejemplo, en Mme Ka de Noëlle Renaud donde el personaje principal nombra más de cien personajes que existen en la obra solo porque se los nombra], del flujo de voces que se cruzan. Por momentos es difícil justificar la aparición de la palabra ... y de saber a quién está dirigida. Difícil también de diferenciar los discursos coherentes de aquellos que se construyen por medio de capas de orígenes diferentes (2006, p. 25).

Más allá de la diversidad de formas que el habla de los personajes ha adquirido en las últimas décadas, más allá de las elecciones formales y de la determinación propia de los conjuntos estilísticos, la palabra teatral asume un nuevo rol en su interacción con los intensos discursos escénicos propios del teatro intermedial. Tanto en el espacio escénico como en el texto postdramático, se produce una nueva jerarquización de los sistemas narrativos, lingüísticos, visuales y auditivos, creando espacios de resonancia entre el habla del personaje, el universo escripto-visual, la trama escripto-sonora y las arquitecturas escenográficas. En diferentes momentos del movimiento escénico pueden producirse subordinaciones y suplantaciones cuando los cuerpos presenciales son absorbidos o transferidos hacia los universos virtuales. Mientras que la palabra sigue su demarcación escénica inmutable a los mundos envolventes, o en el otro extremo del espectro escénico, a la oscuridad total. Josette Feral da un buen ejemplo de esto al referirse al teatro de Robert Lepage. Dice que aun cuando en Les sept branches de la rivière OTA "la actuación reside [o se inscribe] principalmente en el cuerpo, también son [los cuerpos] elementos del decorado, pequeño engranaje indispensable pero no exclusivo del conjunto" (2013, p. 58). Sostiene luego Feral, siempre refiriéndose a la obra apuntada y a la Trilogía del Dragón, que:

Provistos de una importancia igual, los cuerpos se densifican, pasando a ser componentes esenciales de la escena, transformados en materia, determinando un espacio, alineando una 
trayectoria, como movidos por (y con) todos los elementos del escenario, registrando e impulsando un ritmo, fundiéndose en el conjunto (2013, p. 58).

La escena, en este caso, funciona como una construcción de capas múltiples, incidiendo directamente en la aparición de los mundos imaginados y exigiendo del espectador, ante este teatro de la imagen, un entrenamiento propio de esa nueva literacy, como uso y apropiación de los medios en el cauce de una constante realfabetización comunicativa a la que aludimos al comienzo de esta exposición. Los procesos intermendiales tienen como punto de partida la presencia de dos o más sistemas mediales que, puestos en marcha en un espacio comunicativo de convivencia interactiva, designan y construyen en sus movimientos conjuntos un pasaje, una región de tránsito en la que se inscriben las respectivas travesías, dejando una marca común que las une y las redetermina.

La intermedialidad propone el estudio de esa región de tránsito, de las formas en las que la travesía produce y se produce. El objeto resultante de los procesos intermediales abre el espacio de la recepción hacia un precario equilibrio que se resuelve a cada momento, en el desplazamiento posible, hacia lo otro, a través de lo otro, y este desplazamiento, a la manera de un cometa, permite que lo que puede ser visible se vuelva visible en el momento único e irrepetible de cada observación. De aquí que, en la exigencia de una observación recodificadora, el conocimiento posible de los procesos intermediales y de los objetos resultantes de dichos procesos, sólo tiene lugar desde y a través del uso y apropiación de los sistemas intermediales implicados.

La regeneración estética que estos procesos inducen y provocan, crea o propone una relación cada vez más compleja entre el manejo e implementación de las técnicas y la construcción conceptual del objeto artístico puesto a circular en el ámbito de una identidad faltante, de la precaria realización de identidades múltiples actuando como flujo de voces que, al cruzarse, dejan marcas perceptibles en el contexto de la sociedad intermedial. Estos nuevos estados de vivencia no son sino la materia prima por medio de la cual podemos generar nuestra propia manera de convivir en el marco de un espacio activo en el que es posible reconocer y reconocernos.

Finalmente, esto nos lleva a plantearnos las posibilidades de lo que llamaremos escritura intermedial para la escena. Específicamente, proponemos aquí el uso del término escritura intermedial para una forma de creación textual o escénica que, desde la base conceptual, se constituye como una serie integrada de escrituras mediales. Si partimos de la idea que la escritura intermedial, no es una escritura de base unimedial a la que se suman luego otras intervenciones mediales, para completar de alguna manera una presentación escénica, debemos reconocer entonces, que ninguno de los medias iniciales actuando independientemente es 
capaz de soportar la idea de la obra y que esa idea, surge y se determina en el transcurso de las interacciones mediales.

En lo que respecta a la creación teatral, la obra de arte en el espacio escénico, entendemos el concepto de escritura escénica como una escritura determinada y resuelta por el trabajo del director sobre la escena. Específicamente, hacemos referencia a todo aquello que se registra en un grado de secuencia creativa que tiene que ver con las escrituras que en principio no están determinadas o inscritas en un texto dramático. En ese proceso de escritura escénica hay que inscribir también el trabajo creativo del actor, porque hay una parte de la escritura escénica que es también resultado del trabajo de creación de un personaje. Podemos decir que la escritura escénica es el proceso de ensamble de una serie de discursos y escrituras parciales puestas en un funcionamiento común, según la visión creativa de un metteur en scène. Y hago aquí la distinción entre director y metteur en scène, porque el director asume, fundamentalmente, la dirección de los actores y la puesta en escena es, justamente, el ajuste, la puesta en funcionamiento del conjunto de lenguajes que constituyen la escritura escénica.

En una propuesta tradicional, el autor dramático produce una idea, básicamente, transformada y trasmitida en diálogos, lo que da como resultado un contexto de traducción de una fábula en una dinámica de diálogo, a lo que se suman algunas indicaciones (generalmente limitadas) de los espacios y las sensorialidades escénicas y en ciertas ocasiones, la descripción de algunas conductas emocionales del personaje. Pero si se considera la creación dramática como la realización de un pensamiento escénico puesto en literatura, entonces deberíamos considerar el texto dramático como un texto genéticamente intermedial, híbrido en su doble condición de arte en el espacio y de literatura abierta. Entre literatura y escena, la escritura dramática propone un conjunto de mediaciones; estas mediaciones - a futuro- están integradas en el acto de la escritura dramática que incorpora las formalidades de la acción teatral condicionada por la convención que determina que este texto no es en sí un texto para la literatura, sino un texto para resolverse a través de una activación escénica, y, por ello, por medio de una poética determinada por el conjunto de convenciones teatrales. Siguiendo esto, podríamos también decir que el texto dramático posee una doble condición, que es un texto doble medial.

Ahora bien, la escritura intermedial de un texto postdramático propone, sin embargo, en el comienzo del proceso creativo, un orden conceptual diferente, una integración predeterminada de lenguajes que se configuran, únicamente, en sus relaciones intermediales. Así, en la escritura intermedial el diálogo no es algo que precede y predetermina el encadenamiento escénico, sino, por ejemplo, una posible relación entre una acción verbal y una imagen virtual.

Observemos un caso hipotético: consideremos un director que elige trabajar un texto de Ibsen, por ejemplo, Casa de Muñecas. Supongamos que el creador escénico pretende 
realizar una puesta en escena que integre una presencia importante de imágenes virtuales, reproduciendo íntegramente el texto del autor, pero al mismo tiempo, la escritura escénica desarrolla, en una línea de imágenes virtuales, la condición de la mujer en la época actual. La contraposición de esa mujer que es la Nora original y lo que sería Nora en el año 2015 daría probablemente como resultado, por contraposición, un personaje global diferente al ideado por el autor. En el caso propuesto se estaría realizando lo que podríamos identificar como una escritura escénica intermedial.

Contrariamente al ejemplo anterior, la escritura posdramática intermedial asume desde el comienzo la idea de la intermedialidad escénica, construyendo un objeto textual que no se limita a la puesta en relación de diferentes medias a partir de las técnicas propias de la puesta en escena actual. Más bien, inicialmente, se propone crear un espacio escriptural en el que ciertas partes del discurso son asumidas por distintos lenguajes mediales en sus procesos combinatorios. En este caso, ya no será necesario hablar de la batalla y describir la batalla como lo hace Shakespeare, ya no tendremos que hablar del barco y de las llamas en La Tempestad, sino que lo que producirá, será una reducción narrativa de la escritura dialógica, transfiriéndola a una escritura tecno-visual, asumida por todas las técnicas de la imagen, ya sean mecánicas o numéricas. Lo mismo ocurre con la dramaturgia sonora y la dramaturgia espacial o escenográfica. La escritura intermedial es necesariamente una escritura compositiva (en el mismo sentido que le da Appia a este término dentro de la creación teatral). No se trata de escribir un texto dramático, hacer una lectura dramatúrgica, hacer un diseño de puesta en escena, conducir la dirección de los actores y luego, proponerle a un concepto sonoro que componga una trama con ciertas músicas para completar un ambiente. Lo mismo con un concepto de video cuya función sería la de producir imágenes que luego serán insertadas en el espacio escénico, en convivencia simple con las ambientaciones sonoras, los diálogos y las acciones verbales de los personajes.

Para que exista una obra que sea el resultado de una escritura intermedial, es necesario considerar todos los elementos que permiten componer un texto, desde la trama dialógica, las tramas sonoras, los universos de la imagen virtual y mecánica, los medios ambientes lumínicos, los textos luz, para componer una obra en la que conceptualmente hay escrituras específicas que se entrelazan produciendo un sentido que solo nace de ese cruzamiento entre los lenguajes y no de la suma de ellos. Específicamente, se propone el uso del término escritura intermedial para un tipo de escritura que, desde la base conceptual y técnica, integre una serie combinada de escrituras mediales. Esto determinará la composición de una obra que asume en su configuración conceptual la participación irremplazable de una serie de medios interactuando y de cuyas zonas de acción mutua surge el sentido y la línea fundamental de acción de la obra. 
Supongamos la presencia en un texto postdramático, de una proposición escripto-gestual, una intervención coreográfica a la que se suman una presencia sinfónica, una presencia lírica y una presencia teatral (teatral en el sentido de personajes teatrales). En el transcurso de la acción creativa, este funcionamiento de escritura multimedial, va proponiendo ciertas prioridades escénicas a ciertos lenguajes. Pero estos pasajes de protagonismo medial, están considerados porque hay una zona en la que, de hecho, los medios en su conjunto producen la idea escénica, y otras veces en las que no puede haber una presencia de uno de esos medios si es necesario un pasaje de relación intermedial.

En la escritura intermedial, lo que puede identificarse como procedimiento técnico son ciertos momentos de protagonismo de una escritura sobre otra, de un medio sobre otro, pero no una simple suma o alternancia de las condiciones mediales, sino una presencia medial siempre integrada desde el pensamiento creador inicial.

Lo que resulta importante y por ello determina esa condición de escritura intermedial, es lo que se produce en la acción conjunta y combinada, en una presencia indisociable que el juego de interacciones determina y produce a través de cada una de las presencias mediales, fundamentalmente en las zonas de hibridación que surgen de esa interactividad medial. Es allí donde podríamos hablar de grados de transmedialidad, según los cuales, lo que se produce en las zonas de fricción - procesos de reconfiguración en los que las unidades del discurso escénico adquieren nuevas conformaciones que tienden a un cierto grado de estabilidad-propone una forma medial múltiple en su inicio genérico, que se insinúa, en su conjunto, como una nueva unidad de mediación.

Finalmente, nos parece fundamental identificar ciertas premisas que parecen necesarias a la producción de una obra postdramática propia de una escritura intermedial. Una de ellas, de suma importancia, radica en la imposibilidad de trabajar en la creación de una escritura intermedial postdramática si se desconocen los elementos técnicos básicos de los diferentes medias en acción. Si la escritura intermedial es posible, se vuelve trascendente la creación de conjuntos didácticos y pedagógicos de formación en creación intermedial para el teatro, incluyendo las nuevas formas de la composición postdramática. La acción creativa va siempre por delante de los desarrollos técnico-pedagógicos y por ello exige de alguna manera que haya posibilidades de estructuras didácticas e implementaciones pedagógicas que las elaboren y las trasmitan. En el campo de las escrituras intermediales para el teatro, en convergencia con los desarrollos actuales de las realidades escénicas, es necesario reunir en un conjunto metodológico las realidades artísticas y los procesos de formación profesional y académica, integrando en ello el concepto de realfabetización que según Mariniello propone y exige el universo de la intermedialidad. 


\section{Referencias}

Bolter, J. D. \& Grusin, R. (1999). Remediation: understanding new media. Cambridge: MIT Press.

Couchot, E. \& Hllaire, N. (2003). L’art numérique: Comment la technologie vient au monde de l'art. Paris: Éditions Flammarion.

Danan, J. (2004). Dossier Mutation de l'action, Presentation, en L'Annuaire théatral, no. 36, p. 9-54.

De Diego, Rosa y Vázquez, Lydia (2001). La Máquina Escénica: Drama, Espacio, Tecnología. Bilbao: Universidad del País Vasco: Euskal Herriko Unibertsitatea

Doeuihi, M. (2008). La grande conversion numérique, (Traducción P. Chemla). Paris: Seuil.

Doeuihi, M. (2011). Pour un humanisme numérique. Paris: Seuil.

Hagemann, S. (2013). Penser les médias au théâtre: des avant-gardes historiques aux scènes contemporaines. Paris: L'Harmattan.

Hébert, Ch. \& Perelli-Contos, I. (2006). Théâtre et nouvelles technologies: un espace d'interactions, En Lucile Garbagnati y Pierre Morelli (directores), Théâtre et nouvelles technologies: Editions Universitaires de Dijon.

Higgins, D. (1966). Intermedia. The something else newsletter. New York(1)1.

Jiménez, M. (1997). Qu’est-ce que l'esthétique (Collection Folio essais 303). París: Gallimard.

Lehmann, H-T. (2002). Le théâtre postdramatique, (Traducción Ph.-H. Ledru). Paris: L’Arche

Mariniello, S. (2009). Cambiar la tabla de operación. El medium intermedial. Acta poética 30(2).

Ryngaert, J. P. y Sermon, J. (2006). Le personnage théâtral contemporaine: décomposition, recomposition. Paris: Éditions Théâtrales.

Thenon, L. (2002). Proyectos de formación actoral: La formación del actor y la dramaturgia intermedial. ADE Teatro. Revista de la Asociación de Directores de Escena de España, (92), 172-177.

Thenon L. (2013). Bases epistémicas para una historia del teatro actual (Proyecto de investigación Posdoctoral). Universidad de Costa Rica, Costa Rica. 